\title{
THEORETICAL AND EXPERIMENTAL ANALYSIS OF ROTARY COMPRESSION OF BALL PINS HOLLOW FORGINGS
}

\author{
Janusz Tomczak ${ }^{1}$, Tomasz Bulzak' ${ }^{1}$, Zbigniew Pater ${ }^{1}$ \\ 1 Mechanical Engineering Faculty, Lublin University of Technology, Nadbystrzycka 36, 20-618 Lublin, Poland, \\ e-mail: t.bulzak@pollub.pl
}

Received: 2016.07.15

Accepted: 2016.10 .08

Published: 2016.12.01

\begin{abstract}
This paper presents the chosen results of ball pins hollow forgings forming by means of rotary compression. Theoretical research was based on numerical simulations, conducted using finite element method. The software Simufact was applied for calculations needs. During simulations, kinematics of material flow, strain intensity distribution, damage criterion according to Cockroft-Latham and temperature distributions were determined. Force parameters in the process were also determined and limiting phenomena were identified. Results from FEM modeling were verified in laboratory conditions. Ball pins hollow forgings forming tests were performed in a special forge aggregate. The obtained results fully confirmed the possibility of ball pins hollow forgings manufacturing by means of rotary compression.
\end{abstract}

Keywords: hollow ball pins, rotary compression, experiment, FEM.

\section{INTRODUCTION}

Application of hollow products in machines building is one of the ways of lowering of manufacturing and machines exploitation costs. Smaller machine's mass leads to lowering material wear at the manufacturing stage, yet, during its exploitation, it causes lowering of energy and fuel consumption, exhaust emission and allows to improve technical parameters. Because of that, hollow products are more widely applied as machine's elements. A large group of machine's parts, which can be used as hollow ones, constitute axes and shafts, which due to the character of transferred loads (mainly bending and torque moments) have resistance properties similar to full products, yet, they are considerably lighter than their traditional equivalents [1]. Complete application of hollow elements advantages is possible when their semi-finished products will be integrally formed as hollow using metal forming methods (with retaining small allowance for machining) [2]. Such a solution requires, how- ever, working out advanced metal forming technologies, which allow for manufacturing of hollow products both from full and hollow billet ( in the form of commercial pipes) [3]. According to rating made by Neugebauer et all [4], at present for metal forming of hollow elements are applied such technologies as: roll flowing, cross-wedge rolling, forging on swaging machines and horizontal forging machines, hydroforming, extrusion in cold and hot etc. Majority of the used so far metal forming methods of hollow products and semi-finished products are characterized by large degree of complexity and require application of expensive machines and devices. In the result, effective usage of these processes is possible only at large series and mass production. The specifics of production of a wide group of forging plants is reflected in a large differentiation of the formed forgings assortment, which are often manufactured in small series [5]. In the result, each change of assortment of the manufactured elements is connected with the necessity of large investment expenditure. This causes that in the 
case of small manufacturing series, application of techniques based on metal forming processes is economically unjustified. Hence, it is fully justified to search for alternative metal forming technologies of machines hollow elements, application of which will be profitable at small production series. Especially favorable seem to be here rotary technologies, in which tolls rotate $[6$, 7]. They are characterized by numerous advantages, which include: small forming forces, good resistance properties of products, small tools costs in comparison with other technologies, possibility of products forming from not easily deformable materials.

One of the innovative forming technology of hollow elements which has been recently worked
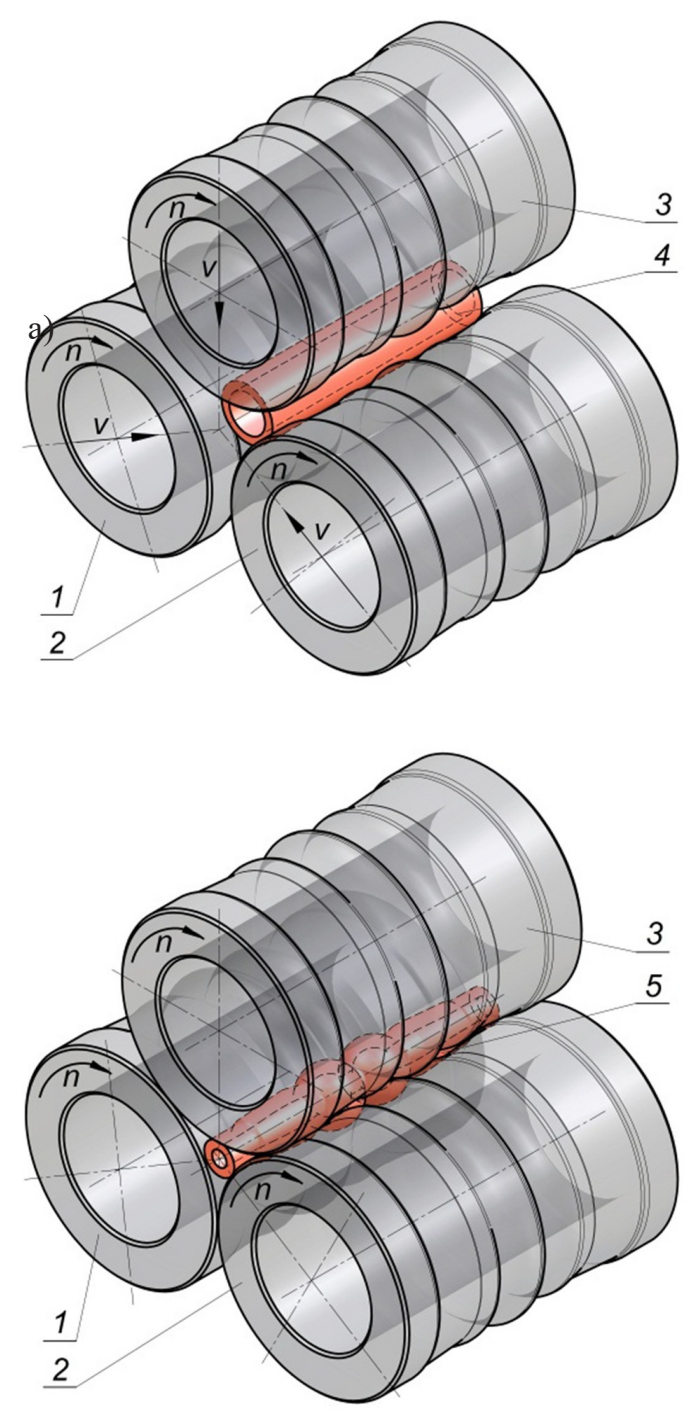

Fig. 1. Schema of rotary compression process of ball pin forging in double configuration: a) the process beginning, b) the process end; 1, 2, 3 - tools, 4 - billet, 5 - ball pin forging out at Lublin University of Technology [8], is rotary compression. This process is based on forming by means of three cylindrical rolls axisymmetrical elements from pipe semi-finished products (Fig. 1).

During the process, tools (three stepped rolls) rotate in the same direction and make translational motion in the radial direction at the same time. The formed semi-finished product (pipe's part) is placed between rolls and during compression it rotates around its axis. In the result of tools action, the change of external diameter of the forging particular steps takes place, which is connected with its wall thickness increase. This phenomenon is favorable due to resistance reasons and allows for retaining constant element resistance, although the external diameter is reduced. A characteristic feature of products formed by means of rotary compression is their axi-symmetrical shape and possibility of billet in the form of commercial pipes application.

The presented forming conception of hollow forgings was positively verified in laboratory conditions. The research works conducted aimed mainly at determining the process parameters influence on the forming course and on the obtained forgings quality [9]. The chosen results of research concerning forming of elementary hollow shafts were presented e.g in works [10-12]. Moreover, the tests of hollow complex geometrically forgings (as multi-stepped shafts) by rotary compression method definitely confirmed the usefulness of the proposed technology for parts manufacturing from pipe semi-finished products. At present, new elements which can be manufactured by means of that method are being searched for. The scope of interests includes: toothed shafts, shafts with worm winding, hollow balls and ball pins, which are discussed in the following paper. The proposed forming method of hollow products is characterized by small implementation costs (simple construction of the machine tool and cheap tools, in the form of stepped rolls). Due to that fact, rotary compression technology has a chance to be applied in small series production, as well as in large-series and mass production.

\section{SUBJECT OF RESEARCH WORKS}

The possibility of application of rotary compression process for manufacturing of hollow ball pins was analyzed on the example of element taken from motorization, which is presented in 


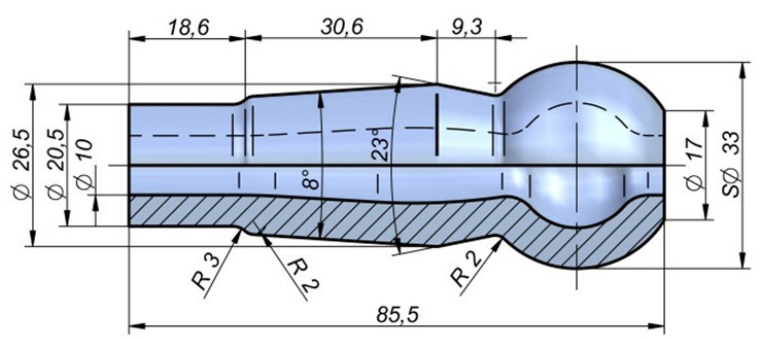

Fig. 2. Semi-finished product of a ball pin with marked important dimensions

Fig. 2. This ball pin consists of a ball - shaped part of the largest diameter, two conical surfaces and a cylindrical part. Due to the element shape, it was proposed to compress the forging in double configuration in order to balance forces acting in axial direction and to lower allowance.

It was decided that forgings would be connected with each other by ball-shaped parts by means of cylindrical connectors (Fig. 3b). At such a position of elements the problem of material free flow in the direction of billet head surfaces is eliminated, which would be present in the case of reverse elements placement. Moreover,

a)

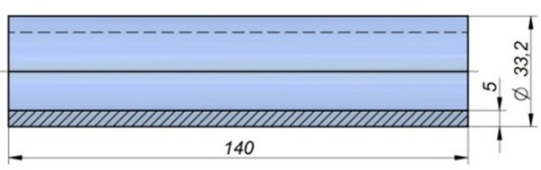

b)

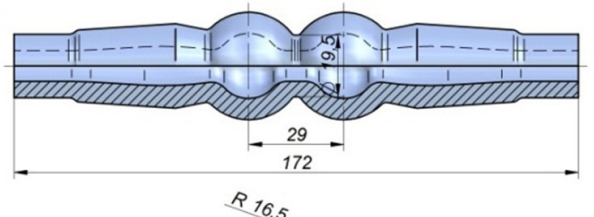

c)

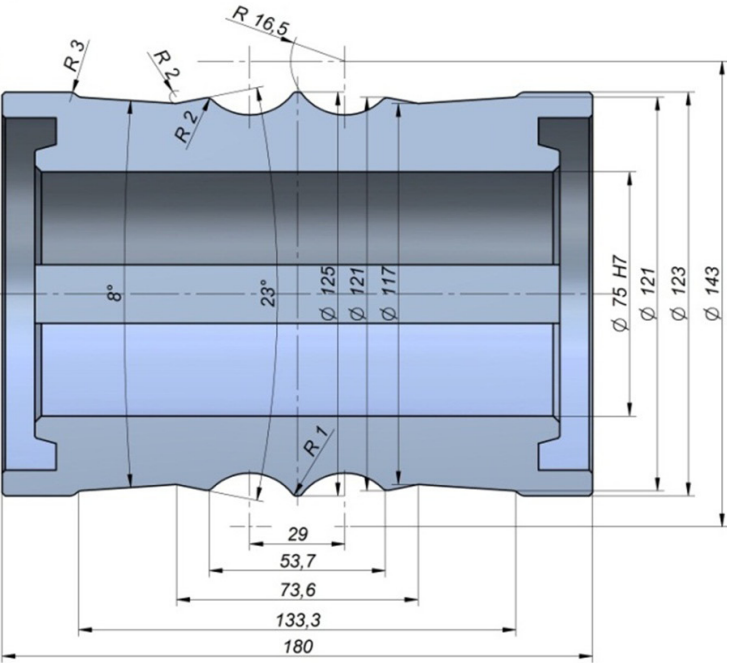

Fig. 3. Design parameters: a ) billet, b) ball pin forging in double configuration, c ) tool segment forming in the tools central part forging's steps of maximal diameters allows for reduction of the semi-finished product dimensions (its diameter and length).

After forming process, elements are split by means of cutting, realized on disk cutting-off machines. For the tests needs the tools design was worked out (Fig. 3c), which had the shape of stepped rolls, divided along the axis into two segments. Billet dimensions (Fig. 3a) were also assumed; as billet were used parts of commercial pipes of external diameter $\varnothing 33.2$ and length $\mathrm{L}_{\mathrm{o}}=140 \mathrm{~mm}$. What is more, forming steps with maximal diameters in the forging central part allows for reduction of the semi-finished product dimensions (its diameter and length). After forming process, elements are split by means of cutting, realized on disk cutting-off machines. It was also assumed that forming tests of forgings would be conducted with application of billet of various walls thickness, which were equal to $=(3,4,5$ and 6) $\mathrm{mm}$ respectively.

\section{NUMERICAL ANALYSIS OF BALL PINS HOLLOW FORGINGS COMPRESSION}

Verification of the correctness of proposed forming technology of ball pins was made by means of numerical simulation. In calculations the software Simufact Forming was used, which was applied by the Authors for modeling of crosswedge and skew rolling processes. One of the worked out for the analysis needs model is shown in Figure 4. The model consists of three identical

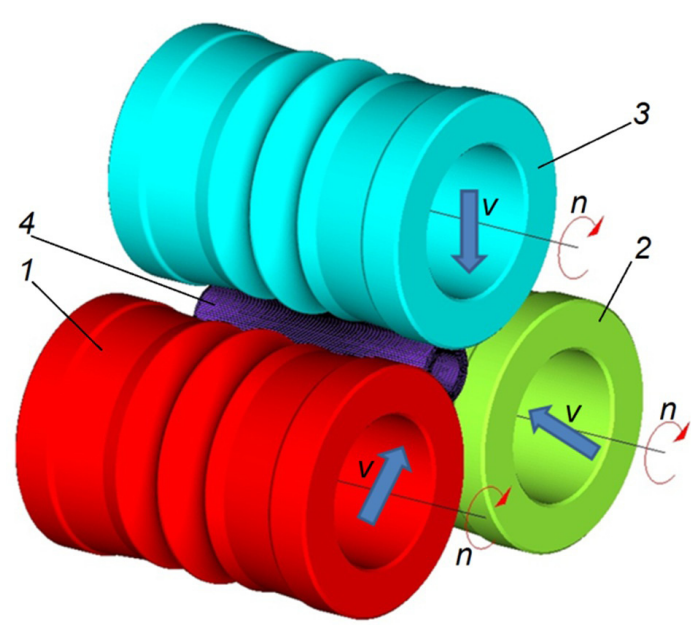

Fig. 4. Applied in FEM simulations geometrical model of the ball pins forging compression: 1,2,3-tools, 4-billet 
tools $-1,2,3$ and billet -4 . Tools in the form of stepped rolls were modeled as rigid bodies. However, billets (pipes parts of type $\mathrm{C} 45$ and external diameter $\mathrm{D}=33.2 \mathrm{~mm}$, walls thickness go and length $\mathrm{L}_{\mathrm{o}}=$ $140 \mathrm{~mm}$ ) were modeled as rigid-plastic bodies by means of 8-nodes element of first category. The choice of this type of steel was purposeful. It is widely used on various parts of machines such as: toothed wheels, shafts, axes, toothed shafts, crank shafts and other mean loaded elements. Material model of steel C45, which was used in calculations, was taken from the applied software library, it was described by the equation:

$$
\begin{gathered}
\sigma_{p}=2859.85 \cdot e^{(-0.00312548 \cdot T)} \cdot \varepsilon^{(0.000044662 \cdot T-0.101268)} \cdot e^{\left(\frac{-0.000027256 \cdot T+0.000818308}{\varepsilon}\right)} . \\
\cdot \dot{\varepsilon}^{(0.000151151 \cdot T-0.00274856)}
\end{gathered}
$$

where: $T$-temperature (within the scope from $700^{\circ} \mathrm{C}$ to $1250^{\circ} \mathrm{C}$ ), $\varepsilon$ - strain, $\dot{\varepsilon}$ - strain velocity.

Moreover, it was assumed in calculations that: billet material at the beginning of the process for all analyzed cases was heated in the whole volume to temperature $1150^{\circ} \mathrm{C}$, yet, tools during frming have constant temperature equal $100^{\circ} \mathrm{C}$. Rolls during the proces rotated in the same direction with the same velocity $n=36 \mathrm{rpm}$ and they moved in the direction of billet axis with constant velocity $v=3 \mathrm{~mm} / \mathrm{s}$. The surface of contact of the formed material with tools was described by constant friction model. Due to the fact that forgings compression process was realized in hot, for calculations needs the limiting value of friction factor $m=1$ was considered. Moreover, it was assumed that heat exchange coefficient between material and tools was $25 \mathrm{~kW} / \mathrm{m}^{2} \mathrm{~K}$, and between material and environment it was $0.35 \mathrm{~kW} / \mathrm{m}^{2} \mathrm{~K}$.

\section{RESULTS OF NUMERICAL ANALYSIS}

Basing on the conducted numerical simulations it was possible to analyze material flow kinematics during rotary compression process of ball pins forgings. No matter what billet walls thickness is assumed, the schema of forging rolling is similar. At the first stage of the process the diameter of forgings extreme steps is reduced, which allows for material closing in the impression made by three rolls. In the next stage of the process, extreme pivots and conical steps are simultaneously formed, at the end, also forging ball-shaped parts are formed. During compression material flows in three directions: radial, causing increase of the wall thickness, axial, leading to increase of the ball pins cylindrical (extreme) parts length and circumferential, not influencing the shape change but only acting on increase of strain intensity in superficial layers. Determined by FEM shape progression of the ball pin forging, formed from semi-finished product with the initial wall thickness $\mathrm{t}_{\mathrm{o}}=6 \mathrm{~mm}$ is shown in Figure 5 .

Performed numerical analysis showed that for all considered cases of compression ball pins forgings reached the desired shape (Fig. 6). Analyzing determined by FEM strain intensity distributions it can be observed that there is present large heterogeneity of material metal forming. Visible concentration of strains in superficial layers is the result mainly of circumferential material flow caused by friction forces during forgings rotation by rolls. It should be mentioned that material flows in superficial layers also in axial direction, which is confirmed by the increase of length of forging extreme steps. It is also crucial that although identical value of reduction ratio is as-

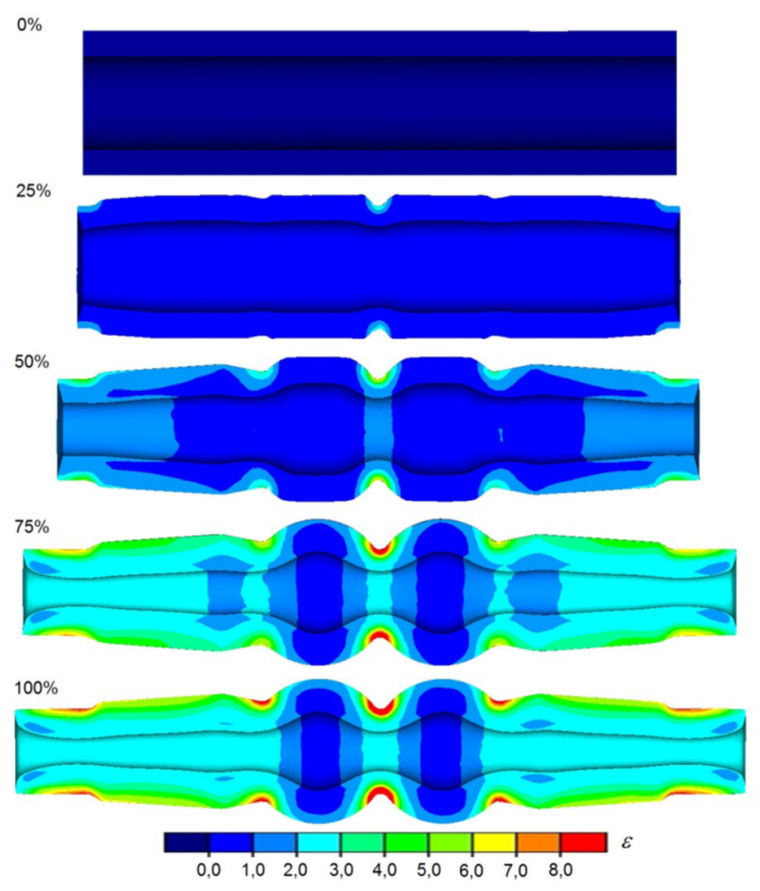

Fig. 5. Determined by FEM shape progression of the ball pin forging with marked distribution of strain intensity 


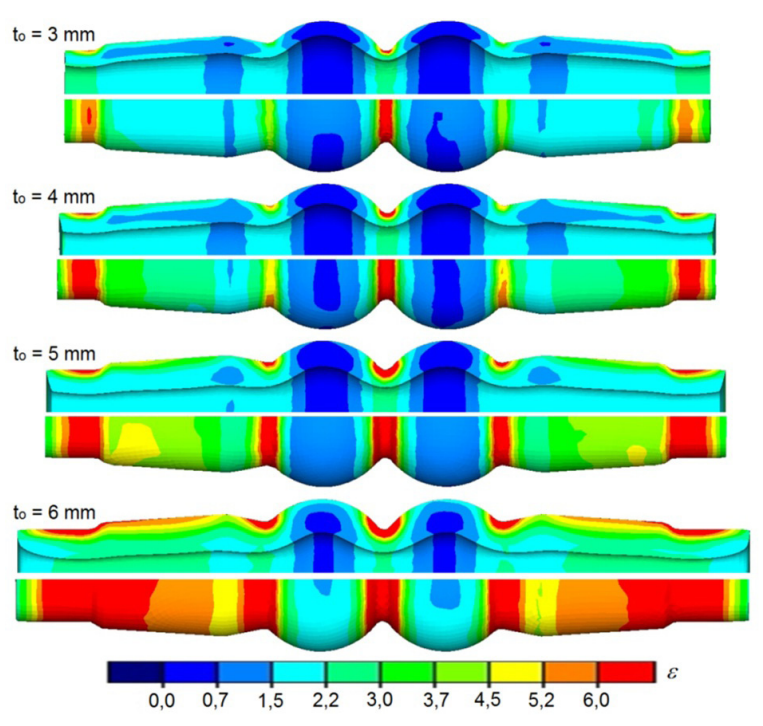

Fig. 6. Determined by FEM strain intensity distribution in ball pins forgings compressed from semifinished products with various walls thickness

sumed for all analyzed cases, strains increase and their larger heterogeneity are observed together with increase of the initial thickness of the semifinished product wall. This is caused by displacement of larger material volume during compression of semi-finished products with thicker walls and larger redundant strains presence (in circumferential direction).

The next Figure 7 shows maps presenting temperature distributions, which were determined by FEM during conducted calculations. As it was foreseen, tendency to intensive material cooling for forgings formed from semi-finished products with small walls thickness can be seen here. For thin-walled billets temperature decreases concern almost whole semi-finished product section. A quite different character have temperature distributions determined during forming of forgings with larger walls thickness. Local (superficial) decrease of temperature is observed here. In these cases, the further is from superficial layers directly contacting the tools, the larger is material temperature. It is obvious that the main cause of temperatures decrease in the formed steps area is the semi-finished product contact with more colder tools. However, it is characteristic that, although the process realization take relatively much time (about 5 seconds), temperature does not decrease below $950^{\circ} \mathrm{C}$, which can be explained compensation of heat loss by plastic deformation work and friction forces work, which generate large amounts of heat.

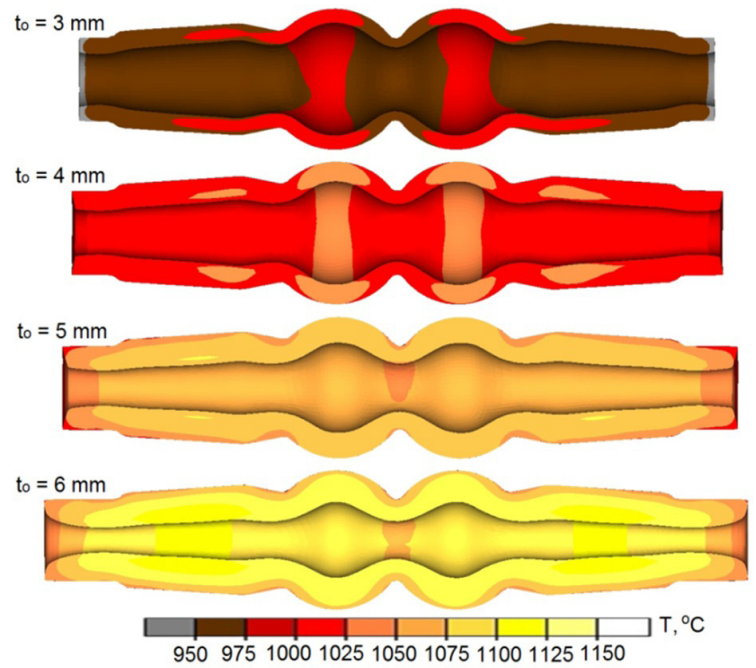

Fig. 7. Determined by FEM temperature distributions in ball pins forgings compressed from semi-finished products with various walls thickness

On the basis of Cockroft-Latham damage criterion, the danger of material cracking was estimated. Analyzing determined by FEM distributions of damage criterion (Fig. 8) it was noticed that during forming of forgings from semi-finished products of the smallest wall thickness, the constant Cockroft-Latham concentrates in the bridge connecting both forgings. It should be, however, mentioned that this is the area of the further forgings splitting, hence, possible cracks in this area will not have influence on the elements usefulness. In the case of forgings forming from semifinished products of larger walls thickness, the damage criterion concentrates in the areas near the hole surface (mainly in the area of formed cylindrical and conical steps). What is more, the danger of cracks presence depends to a large extent on the wall initial thickness. It was observed that together with the increase of initial thickness of the pipe semi-finished wall the damage criterion values increase. This is especially visible in the case of forgings compression from the semi-finished products of the largest wall thickness $\left(t_{0}=6 \mathrm{~mm}\right)$, where noticed extreme values of Cockroft-Latham integral (about 1.2) can exceed limiting values for typical constructional steels at which cracking of material can take place. There is, however, lack of knowledge concerning the influence of complex state of stress (characteristic for rotary compression) on Cockroft-Latham integral limiting values. Yet, the scope of maximal values of this criterion is small. They concentrate 


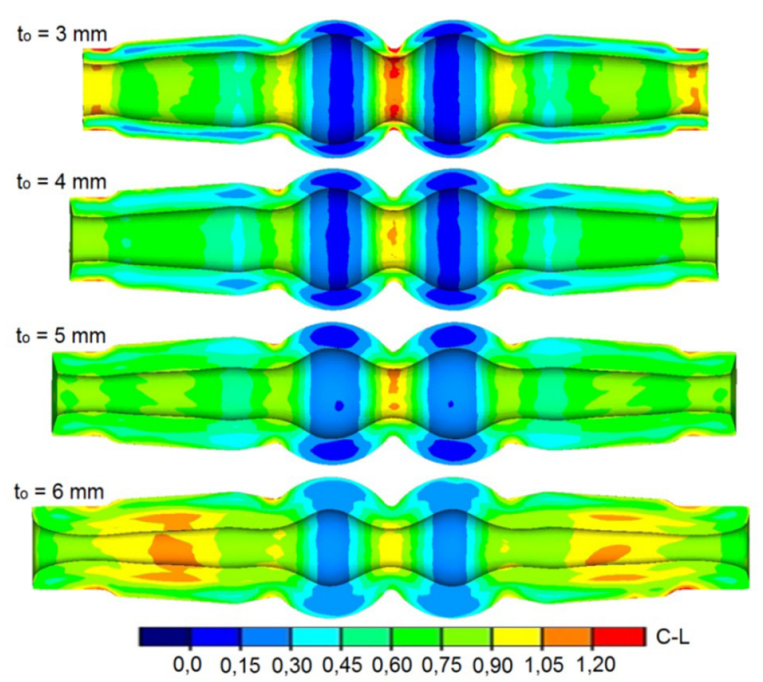

Fig. 8. Determined by FEM distributions of Cockroft-Latham damage criterion in ball pins forgings compressed from semi-finished products of various walls thickness

mainly in layers near the surface, which very often constitute allowance. Hence, in the case of superficial cracks appearance they will be removed together with allowance during machining.

\section{EXPERIMENTAL TESTS OF BALL PINS HOLLOW FORGINGS FORMING}

Positive results of numerical calculations of rotary compression of ball pin hollow forgings made the Authors to conduct the process experimental tests. The aim of research works was verification of numerical models and final confirmation of technological possibilities of the proposed forming method. The research were realized in a forge aggregate for rotary compression of own construction (Fig. 9). The aggregate construction is characterized by segment building and consists of carrying frame -1 , drive unit -2 , gear box -3 , forming rolls stand -4 , hydraulic drive unit of forming rolls -5 , control-feed unit -6 and meter circuit -7 . Rotary compression process was realized in the forming rolls stand, in which three slides with working shafts put in them moved radially. Slides translational motion was synchronized reciprocally due to which the same tools displacement during forgings forming was achieved. For registration of force and kinematics parameters of rotary compression process was applied a measuring system consisting of rotary moment converter, displacement con-

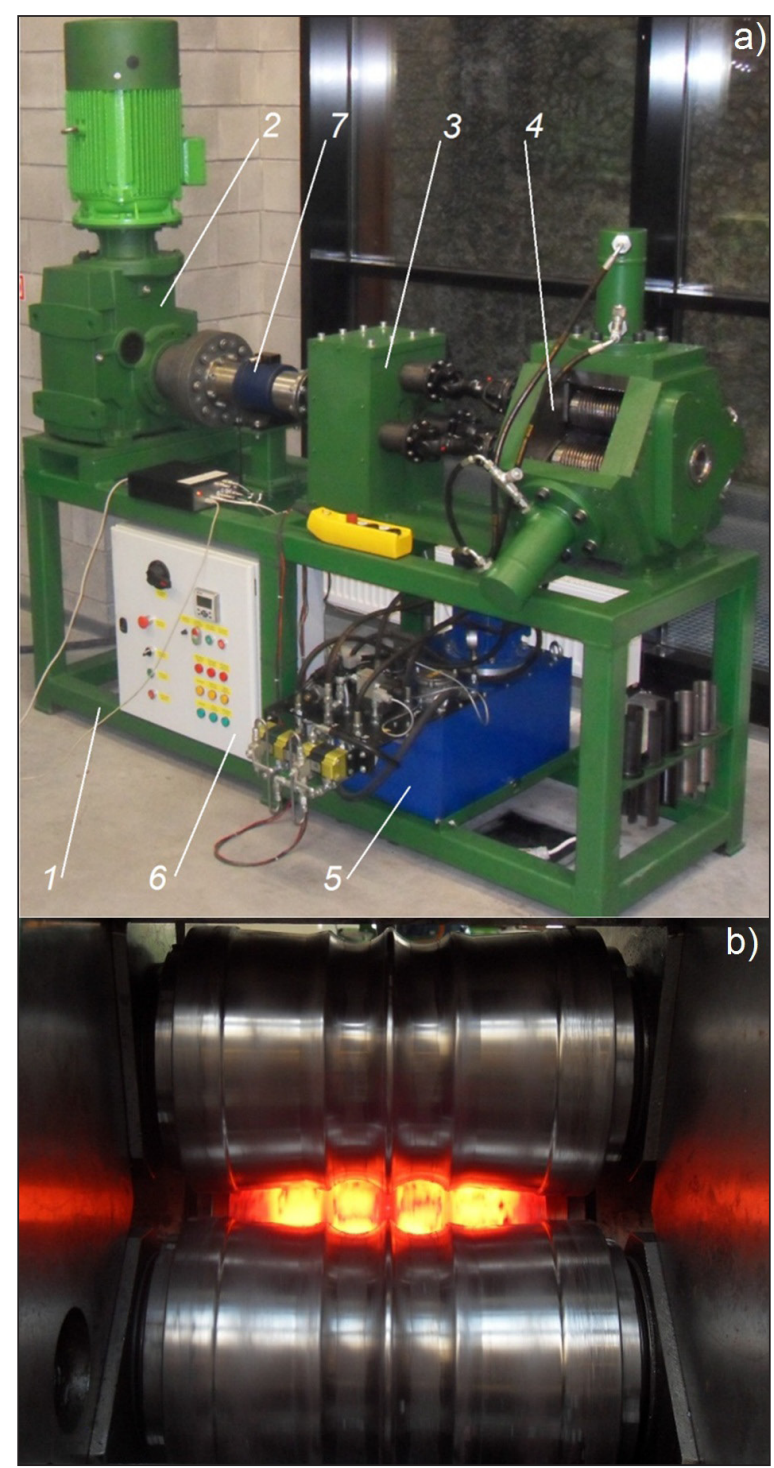

Fig. 9. Aggregate for rotary compression - a) and tools for ball pins forgings forming $-b$ )

verter and pressure converters. Signal from all sensors were registered digitally by means of measuring card and moveable computer. For the research needs, three sets of split tools segments were made, in accordance with Figure 3c.

After tools mounting on the aggregate working shafts (Fig. 9c), a series of hollow forgings of ball pins was formed. During the process similar kinematics, thermal and geometrical parameters were retained as those assumed during FEM simulations. Exemplary forgings formed during experimental tests are presented in Figure 10. Research results fully confirmed the possibility of manufacturing by means of this technology ball pins semi-finished products. The obtained results show quite good geometrical convergence of elements formed during experiment with the shape foreseen 


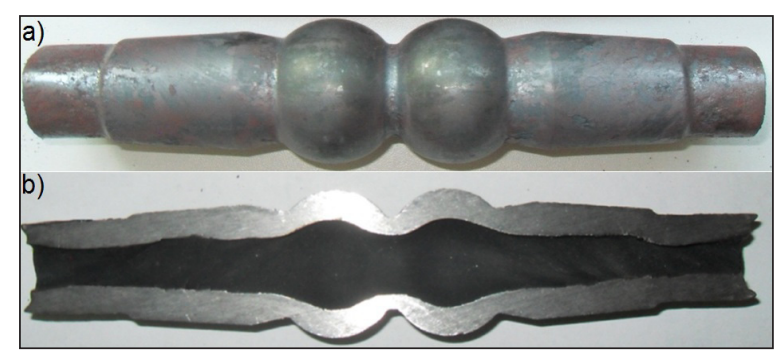

Fig. 10. Formed during experiments hollow forgings of ball pins from billet of wall thickness $t_{o}=5 \mathrm{~mm}$ :

a) view, b) axial section

during simulations. For all forming cases uneven increase of wall thickness and elongation of extreme (cylindrical) forgingm steps were observed.

Comparison of longitudinal sections of forging formed during tests with determined during modeling is shown in Fig. 11. In the case of the experiment it is seen larger elongation of the external step at the cost of smaller increase of wall thickness. It should be, however, highlighted that the obtained wall thickness remains within the assumed area of tolerance (together with allowance for hole final machining).

What is interesting, both research methods point at torsion of cross section of forging alon its axis (Fig. 12). Torsion takes place mainly in the

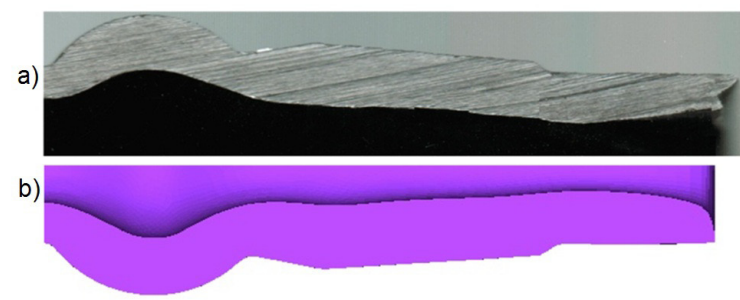

Fig. 11. Axial sections of hollow forging of ball pin formed from semi-finished product of thickness $t_{0}=6$ $\mathrm{mm}$ : a) formed during tests b) determined by FEM

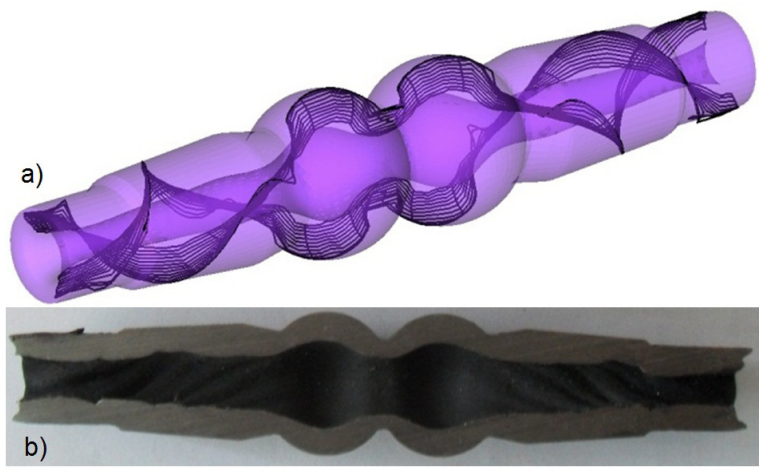

Fig. 12. Torsion of cross section of hollow forging of ball pin:a) determined by FEM, b) shown in the formed forging conical and cylindrical area of the semi-finished product step. It is caused by various circumfeential velocities of steps with different diameters. It was noticed that torsion intensity of cross section increases together with the wall thickness increase. It should be, however, highlighted that the deformed area of the hole surface in the result of buckling and, later, its torsion will be removed during reaming of the hole. Hence, the noticed fault will not have influence on such formed elements usefulness.

During research compression process force parameters were also monitored. Distributions of pressure force of one of the tools and rotary moments on working shaft are presented in Figures 13 and 14. Distributions obtained from calcula-
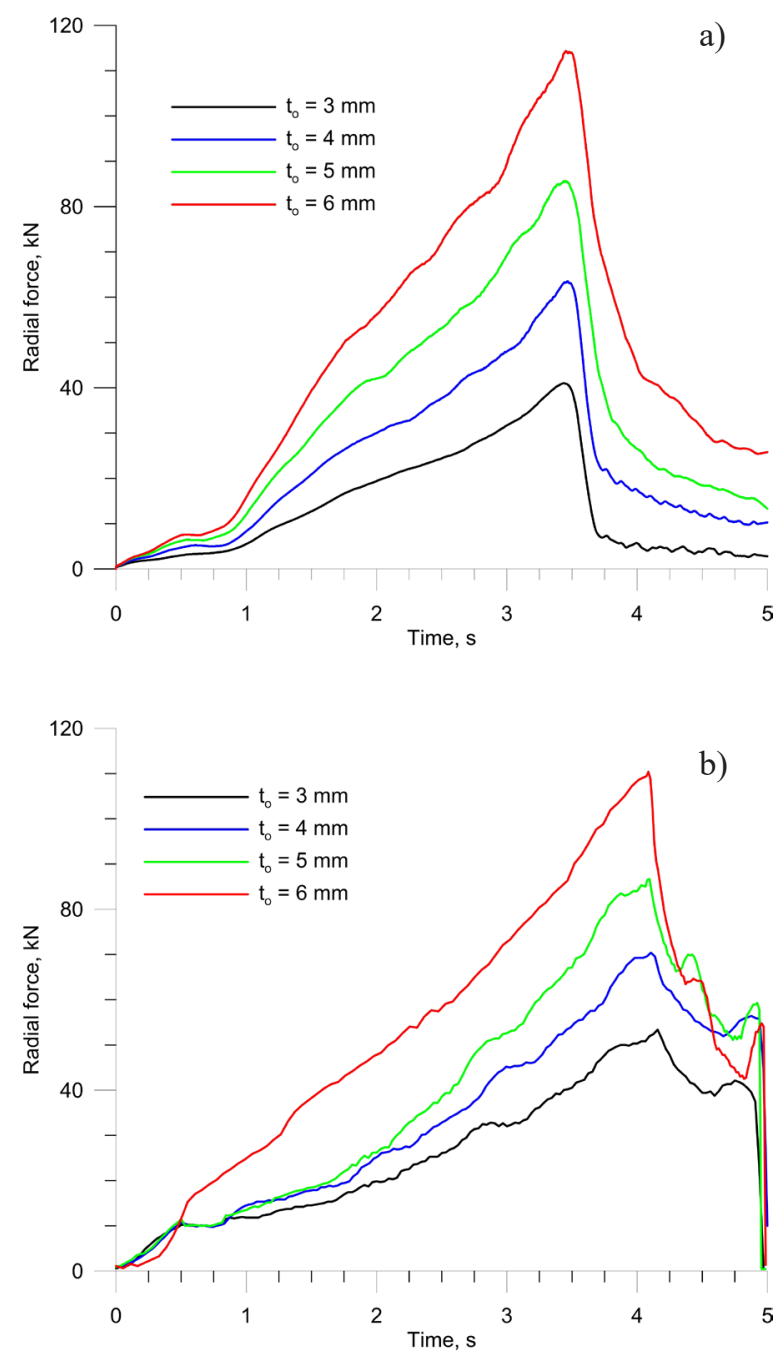

Fig. 13. Course of the pressure force of one of the tools during rotary compression of ball pins hollow forgings from semi-finished products of various wall thickness: a) determined by FEM, b) obtained in experiment 
tions and experiment are close to each other, both qualitative and quantitative.

For all variants, the increase of forces and moments during reduction of billet external diameter is observed-this is the forming stage. The increase of forces and moments results from the material temperature decrease and increase of forgings wall thickness. Next, after tools displacement of value equal half of the ratio $\left(\Delta h / 2=\left(D-d_{\min }\right) / 2\right.$ $=6.85 \mathrm{~mm}$ ), fast reduction of forces and moments values takes place. This is the sizing stage, where inaccuracies of the forging shape are removed. In terms of quantity, larger discrepancies in forces and moments values were noticed for forming process of forgings from semi-finished products of small walls thickness. This is probably connected with larger cooling of material
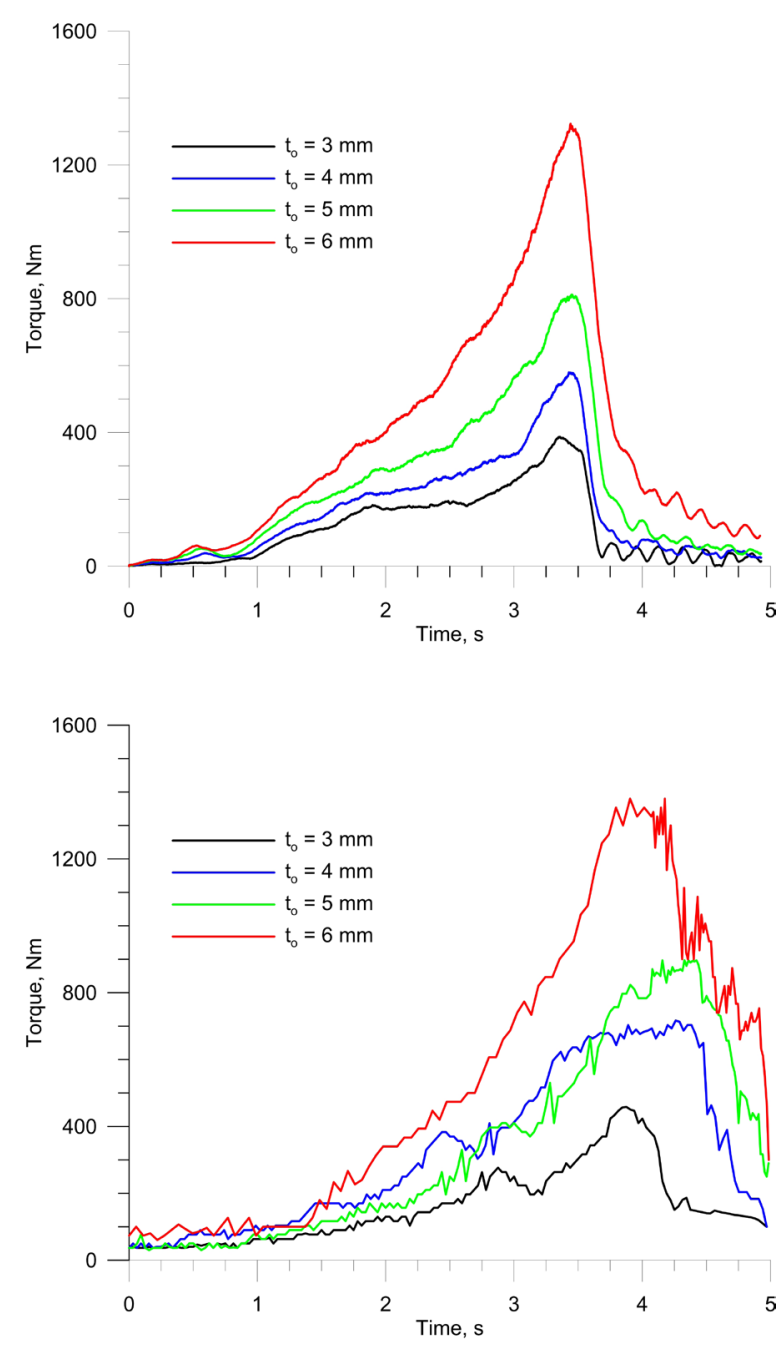

Fig. 14. Course of rotary moments on one of the tools during rotary compression of ball pins hollow forgings from semi-finished products of various wall thickness: a) determined by FEM,

b) obtained in experiment during experiments in comparison with model assumptions. However, in the case of compression of billets with larger walls thickness, larger heat capacity allows for heat loss compensation, hence the observed differences in values are relatively small. In the case of forces they equal $5 \%$, for moments they oscillate within the scope $7 \%$.

\section{CONCLUSIONS}

Constant lowering of construction weight has been in recent years one of the main manufacturing aim in various industrial branches. This is caused mainly by increasing prices of raw materials and energy as well as strong competition on a global market. Weight (mass) reduction can be realized by application of modern ultra-light materials such as: aluminum, magnesium and titanium alloys, and in the result of substitution of full elements by hollow ones. Such an attitude, apart from the construction weight lowering, allows also for reduction of materials and energy consumption. The proposed forming method of axi-symmetrical hollow forgings from pipe semi-finished products is a part of this trend. Thanks to numerous advantages it can compete with other manufacturing technologies of elements of this type.

Basing on the obtained results the following conclusions were formed:

- it is possible to form by means of rotary compression of ball pins hollow forgings within a wide scope of walls thickness;

- on the basis of FEM numerical calculations it was stated that during rotary compression of hollow forgings, large heterogeneity of strains takes place, which results from kinematics of the process realization, wherein with increase of the initial wall thickness greater heterogeneity of strains is observed and larger concentration in the superficial layers of the formed steps;

- in the result of rotary compression wall thickness increase takes place on the pivots whole length, which is favorable due to resistance reasons;

- during forgings forming torsion of forgings cross section appears, which is the result of differences of circumferential velocities of particular semi-finished product steps;

- positive results speak for the further development of the proposed method of forming. 


\section{REFERENCES}

1. Bartnicki J. and Pater Z. Walcowanie poprzeczno - klinowe wyrobów drążonych. Wydawnictwo Politechniki Lubelskiej, Lublin, 2005.

2. Kettner P. and Schmieder F. Manufacturing of hollow transmission shafts via bulk - metal forging. Journal of Material Processing Technology, 71, 1997, 113-118.

3. Neugebauer R., Glass R. and Hoffmann M. Spin extrusion - a new partial forming technology based on $7 \mathrm{NC}$-axes machining. Anals of the CRIP, 54(1), 2005, 241-244.

4. Neugebauer R., Kolbe M. and Glass R. New warm forming processes to produce hollow shaft. Journal of Material Processing Technology, 117, 2001, 277-282.

5. Hirschvogel M. Transmission shaft forgings - technical and economical aspects of new developments. Proceedings of the 9th International Colt Forging Congress, Solihull, UK, 1995, 425-431.

6. Wang L. and Long H. A study of effects of roller path profiles on tool forces and part wall thickness variation in conventional metal spinning. Journal of Materials Processing Technology, 211, 2011, 2140-2151.

7. Urankar S., Lovell M., Morrow C., Li Q. and Kawada K. Establishment of failure conditions for the cross-wedge rolling of hollow shafts. Journal of Materials Processing Technology, 177, 2006, 545-549.

8. Pater Z. and Tomczak J. Rotary compression of hollow parts by cross rolling. Patent europejski nr: EP2422896, 2013.

9. Tomczak J., Pater Z. and Bulzak T. Effect of technological parameters on the rotary compression process. Eksploatacja i Niezawodnosc - Maintenance and Reliability, 15(3), 2013, 279-283.

10. Tomczak J., Bulzak T. and Pater Z. The effect of billet wall thickness on the rotary compression process for hollow parts. Strojniski Vestnik - Journal of Mechanical Engineering, 61(3), 2015, 149-156.

11. Tomczak J., Pater Z. and Bulzak T. The influence of hollow billet thickness in rotary compression. International Journal of Advanced Manufacturing Technology, 82(5), 2016, 1281-1291.

12. Pater Z., Gontarz A., Tomczak J. and Bulzak T. Producing hollow drive shafts by rotary compression. Archives of Civil and Mechanical Engineering, 15(4), 2015, 917-924. 